\title{
Pain and Suffering Awards: They Shouldn't Be (Just) about Pain and Suffering
}

\author{
Peter A. Ubel and George Loewenstein
}

\begin{abstract}
In this paper, we challenge the conventional view that pain-and-suffering awards should be interpreted literally as a compensation for feelings of pain and suffering. People adapt to conditions as serious as paraplegia and blindness, returning rapidly to near-normal levels of happiness, which means that pain-and-suffering awards based literally on pain and suffering would be small. We argue that compensation for these types of conditions should be larger than would be dictated by pain and suffering alone because people legitimately care about more than just the pain and suffering that results from an injury; they also care about a variety of other factors, such as their capabilities to perform various functions, that often do not affect happiness. We propose the outlines of a method for determining noneconomic damages that divides the problem into three judgments, each to be made by the constituency most competent to make it.
\end{abstract}

\section{INTRODUCTION}

The question of how, or even whether, to value damages associated with pain and suffering is of critical importance for legal practice and theory. Empirical studies have found that noneconomic damages account for a large fraction of personal injury tort suits (Viscusi 1988), and the difficulty of placing a monetary value on such damages is often held responsible for arbitrary, capricious awards (Abel 2006). Geistfeld (1995), for example, estimates that the severity of a victim's injury accounts for

PETER Ubel is the George Dock Collegiate Professor of Internal Medicine at the University of Michigan. George loewenstein is the Herbert A. Simon Professor of Economics and Psychology at Carnegie Mellon University. We thank Cynthia Estlund, Sam Gross, an anonymous reviewer, and participants at the conference for helpful comments and suggestions.

[Journal of Legal Studies, vol. 37 (June 2008)]

(C) 2008 by The University of Chicago. All rights reserved. 0047-2530/2008/370S2-0008 $\$ 10.00$ 
only 40 percent of the variation in pain-and-suffering awards, with the remainder potentially attributable to ostensibly unjustifiable factors such as race, gender, and the perceived attractiveness of the victim.

While experts disagree about what actually influences juries in making these awards, they largely agree about what ought to influence juriesthey should base pain-and-suffering awards on how much misery a victim will experience due to an injury. In other words, pain and suffering, as applied to legal awards, should be interpreted literally-in hedonic terms. Thus, Geistfeld (1995, p. 781) defines pain and suffering as “a category of damages including not only physical pain, but also a wide range of intangible injuries such as fright, nervousness, grief, anxiety, and indignity." All of these intangible injuries, it can be seen, are varieties of feeling states as opposed to objective outcomes. Schwartz and Silverman (2004, p. 1045) cite the judgment of an appellate court in California to the effect that "[t]he standard pain-and-suffering instruction . . . describes a unitary concept of recovery not only for physical pain but for fright, nervousness, grief, anxiety, worry, mortification, shock, humiliation, indignity, embarrassment, apprehension, terror or ordeal." In this list, only the last element allows for any interpretation other than as a hedonically charged feeling state. All the other papers that we were able to locate imply a similarly hedonic perspective.

In this paper we question whether pain and suffering should, in fact, be interpreted in literal, hedonic terms. Drawing on our own and others' research on the measurement and valuation of health states, we argue that while pain and suffering do warrant inclusion as an element of awards, hedonic interpretations of the concept have illogical and normatively unacceptable implications for award amounts.

Several scholars have dwelled on the nub of the problem with the hedonic interpretation of pain and suffering-the phenomenon of adaptation. As we document in some detail, most people adapt substantially to diverse conditions as serious as paraplegia, kidney failure, and blindness, returning to close to baseline levels of happiness after a brief period of adjustment. In Section 2, we review research showing that such adaptation is real and not an artifact of measurement problems; people with these conditions really do experience high levels of happiness. However, as we document in Sections 3 and 4, three groups of people-those who do not have such conditions, those who do have the conditions, and even those who used to have the conditions but recovered from them-display great consistency in the desire to not have the conditions.

We believe that the reason for the discrepancy between hedonic mea- 
sures and stated preferences (as well as preferences revealed by protective and remediative measures) is that people care about many things that are not purely hedonic, such as meaning, capabilities, and range of feeling and experience. If this is the case, it would be seriously misguided to ignore the expressed distaste of all three groups for the health conditions in question and to base valuations of noneconomic damages on a notion of well-being that is far narrower than that adopted by individuals themselves.

In Section 5, we propose the outlines of a method for determining noneconomic damages that, we believe, avoids many of the egregious problems of the current system. ${ }^{1}$ Our method minimizes problems created by hedonic adaptation and is designed to circumvent the challenges that juries would face in balancing hedonic and nonhedonic losses when determining awards. It also minimizes several other major problems that plague pain-and-suffering awards, including horizontal and vertical inequities in compensation, discrepancies between awards based on willingness to pay versus willingness to accept, and arbitrariness that arises from the fact that juries evaluate a given injury in isolation-that is, without considering the range of possible injuries-a task that people are not well suited to accomplish. The proposed procedure divides the valuation problem into three judgments, each to be made by the constituency that is most competent or otherwise best equipped to make it.

Before plunging in, we should note that we lack legal training and that, therefore, there is a high likelihood that we will overlook important legal issues. Our expertise is in the psychology of judgment, decision making, adaptation, and valuation of health states. In this paper, we bring some of the insights from this research to bear on the problem of valuing pain and suffering.

1. Our emphasis in this paper is on awards for pain and suffering. We recognize that there are other categories of noneconomic damages, such as awards for hedonic damages. For example, Bagenstos and Schlanger (2006) distinguish pain-and-suffering damages, which compensate people for physical discomfort and negative emotions, from hedonic damages, which compensate people for limitations on their ability "to participate in and derive pleasure from the normal activities of daily life" (p. 3). Similarly, Price (1993) provides evidence that courts consider hedonic damages to refer either to a loss of enjoyment of life or to loss of life's pleasures. By these definitions, a person who is permanently comatose, or even someone who has died, has suffered hedonic damages and deserves compensation even though neither would be in a position to experience pain or suffering. Although our paper focuses on how to value pain-and-suffering awards, many of our arguments also apply to hedonic damages. In both cases, we think the emphasis of the awards should be broadened to move beyond purely hedonic assessments. 
S198 / THE JOURNAL OF LEGaL STUdies / VOLUME 37 (2) / JUNE 2008

\section{HEDONIC ADAPTATION}

\subsection{Hedonic Adaptation Defined}

Hedonic adaptation refers to any action, process, or mechanism that reduces the affective consequences-emotional effects-of an otherwise stable circumstance (Frederick and Loewenstein 1999). In the context of tort claims, hedonic adaptation occurs whenever a person's postinjury health status remains stable but his emotional response to the injury fades.

Hedonic adaptation can be aided by other forms of adaptation. For example, people can physically adapt to disabilities. Early in their disability, people may have a hard time performing certain activities of daily living. But over time, through physical therapy and the use of assistive devices, their ability to perform such activities tends to increase.

Hedonic adaptation can also be aided by changes in people's social or work environments. A person whose employer is willing and able to accommodate his injury may be able to regain satisfaction from work, or even achieve new, higher, levels. Even if a person's injury precludes him from performing his previous job, he may find a new line of employment and thereby regain some of his previous well-being.

Hedonic adaptation is rarely complete, but in a wide range of circumstances, it is surprisingly strong. For instance, one study found that people with quadriplegia reported a frequency of negative affect similar to that of control respondents (Wortman and Silver 1987). Another study observed almost no difference in quality of life or psychiatric symptomatology in young patients who had lost limbs to cancer compared with those who had not (Tyc 1992).

In one of our own studies (Riis et al. 2005), we surveyed 50 dialysis patients and 50 healthy control subjects, matched by age, race, education, and gender, and asked each group to provide global estimates of the moods they experienced in a typical week: how much time they spent in a very unpleasant mood $(-2)$, unpleasant mood $(-1)$, neutral mood $(0)$, pleasant mood $(+1)$, and very pleasant mood $(+2)$. We also asked them to estimate the moods they thought they would experience if their health changed, with healthy controls imagining that they developed kidney failure and dialysis patients imagining that they had never had kidney failure.

As shown in Table 1, and consistent with adaptation, both healthy controls and patients reported that their mood in a typical week was 
Table 1. Mood Estimates $(-2$ to +2$)$

\begin{tabular}{lcc}
\hline & Current & $\begin{array}{c}\text { Predicted If in the } \\
\text { Other State of } \\
\text { Health }\end{array}$ \\
\hline Healthy control subjects & .61 & -.17 \\
Dialysis patients & .78 & 1.10 \\
\hline
\end{tabular}

positive for the majority of their waking hours, and indeed there was no statistically significant difference in the moods of those two groups.

Hedonic adaptation is not universal, across either people or conditions (Lucas et al. 2004; Oswald and Blanchflower 2004; Lucas 2005). Some conditions appear to defy adaptation more than others, and some circumstances impede adaptation (Ubel 2006). For example, paradoxically, and perhaps surprisingly, the prospect of hope for relief of a condition can impede adaptation to it. ${ }^{2}$ Inevitably, also, there are individual differences both in general propensity to adapt and in ability to adapt to specific conditions (Smith et al. 2005).

\subsection{Is Hedonic Adaptation Real?}

Given the subjectivity of well-being measures, it is reasonable to ask whether hedonic adaptation is real. Supporting such reservations, researchers have documented a number of biases that affect subjective reports of well-being. For example, people's self-reports of how happy they are "in general these days" are powerfully influenced by how happy they are at the moment when they respond, including fluctuations that depend on random factors such as whether the sun is shining when they are asked (Schwarz and Strack 1999). People also tend to naturally "norm" their responses relative to points of reference, such as the people with whom they spend time. A patient who spends time with other patients, therefore, is likely to report higher levels of welfare than one who spends time with healthy people. Nevertheless, a series of studies

2. See Frederick and Loewenstein (1999) for limited evidence on this point. More definitively, in Smith et al. (2008), we asked patients who had just received colostomies to rate their own happiness and life satisfaction and then provide updates about their state of mind at regular intervals thereafter. The main focus of the study was a comparison of the trajectory of happiness and life satisfaction of patients whose colostomies were irreversible with those whose colostomies were potentially reversible at some point in the future. Consistent with prior research, patients with irreversible colostomies displayed indications of adaptation almost immediately after they underwent the procedure. Those with reversible colostomies displayed chronically low levels of happiness and life satisfaction, with little improvement over time. 
we have conducted have convinced us that hedonic adaptation is real and not an artifact of measurement problems.

One possible problem with the measures of happiness that have informed studies of adaptation is that when asked vague global questions about happiness, people with health problems may be motivated to minimize their severity and thus may provide overly rosy reports of their own well-being. To test if that was the case, in our dialysis study (Riis et al. 2005), in addition to asking patients and healthy control subjects for global evaluations of well-being, we also elicited self-reports of moment-to-moment happiness from both groups using an ecological momentary assessment method for an interval of 1 week. We sent both groups home with Palm Pilots that were programmed to beep at random points during the day and ask subjects about their mood. We assumed that they would be less likely to provide overly rosy reports of their well-being when asked to report "the mood you were experiencing when this Palm Pilot beeped" than when asked more vague and global questions about mood. The data from the Palm Pilots showed that the moods of patients and controls were strikingly similar, with both groups reporting significantly more positive than negative affect, and with neither group reporting significantly better moods than the other. This finding provides strong evidence that patients with kidney failure really do emotionally adapt to their illness.

Another vulnerability of measures of happiness based on subjective ratings is the problem of scale recalibration: when people's circumstances change, their interpretations of these subjective scales might systematically change in response. For example, following the onset of an illness or disability, a person may spend more time with other people who are sick or disabled, and when asked to report his happiness on a 0-100 scale, he may automatically compare his own happiness to that of other sick people. ${ }^{3}$ Alternatively, people who have experienced ex-

3. In fact, we found evidence of scale recalibration in an experiment we conducted among participants in the Health and Retirement Study, a large, nationally representative sample of people 50 years and older in the United States (Ubel et al. 2005). In a random subset of 1,031 participants, we asked people to report their overall health on a 0-100 scale. Across participants, we randomly varied the definition of 100 on the scale to represent "perfect health," "perfect health for someone your age," or "perfect health for a 20-yearold." Participants' responses supported the existence of scale recalibration. People with the scale labeled "perfect health" or "perfect health for someone your age" gave similar ratings (73.1 and 72.9, respectively, not significant), whereas people with the scale labeled "perfect health for a 20 year-old" gave lower ratings (with a mean of $65.0, p<.001$ ) than the other groups. 
treme misery during the initial phase of adjustment to an illness or disability may anchor the bottom of the scale on the low point of their experience, which would tend to raise subsequent reports of well-being. Having had paraplegia for some period of time, a person might rate himself at 80 on the scale only because he realizes how much he has improved from his despair immediately following the onset of the condition.

Mixed evidence that scale recalibration could be a problem was obtained in a telephone interview study of 256 Parkinson's patients (Smith et al. 2006a). In the lead-in to the interview, half the respondents were informed that researchers were "calling people with Parkinson's disease to find out about their life satisfaction and well-being." The other half were informed that researchers were "calling people in the northeastern United States to find out about their life satisfaction and well-being." This design allowed them to test whether patients, when told that the interview was part of a study of Parkinson's disease, automatically norm their responses relative to other Parkinson's patients. Consistent with such norming, respondents reported greater health satisfaction when the survey was introduced as a survey of Parkinson's patients rather than the general population. However, this recalibration did not generalize to ratings of general life satisfaction; respondents reported similarly high levels of life satisfaction under both conditions. Thus, patients' high levels of life satisfaction cannot be attributed to conversational context.

Two other studies further explored the impact of the measurement scale on self-reports of happiness. In Baron et al. (2003), we assessed people's quality-of-life ratings for a series of common health conditions. Across ratings, we varied whether or not the response modes were ambiguous. We speculated that if scale recalibration accounted for the high ratings given by patients, then patients should provide lower ratings relative to healthy persons if they responded on a more ambiguous scale. No such effect occurred.

In Lacey et al. (forthcoming), we asked 407 patients with diabetes and a comparison group of 418 people without diabetes to rate a series of health conditions (such as emphysema and quadriplegia) and conditions unrelated to health (such as an unpleasant boss and a chronically difficult commute to work) on a 0-100 quality-of-life rating scale. Upon completing this task, we asked them to rate what their quality of life would be if they had diabetes requiring daily insulin injections. One goal of the study was to see if patients with diabetes would use the scale differently than healthy persons. If patients with diabetes view their lives 
more positively than they otherwise would because they use the scale differently, then they should rate not only the disease scenario but also emphysema, unemployment, and an unpleasant boss more highly than healthy people would. As predicted, diabetes patients gave higher quality-of-life ratings for the disease scenario than did healthy people $(p<$ .01). However, we found no evidence for scale recalibration, because both groups of subjects evaluated items other than diabetes nearly identically.

In summary, the best evidence to date suggests that hedonic adaptation is substantial following a wide range of life circumstances. There-

fore, people with a wide range of tort-related injuries are likely to adapt to their injuries and experience long-lasting happiness despite living with a chronic injury.

\section{PREFERENCES VERSUS HAPPINESS}

Given the apparent reality of hedonic adaptation, it can be seen that valuations that interpret pain and suffering in a literal, hedonic fashion would assign little negative value to a wide range of conditions beyond that associated with a typically brief (albeit sometimes severe) period prior to adaptation. Yet there is ample evidence that people have a strong preference to be in a healthy state, even after they have adapted hedonically to a health condition.

Evidence of a distaste for illness and chronic disability comes from myriad studies that assess the preference for health states using decisionbased (as opposed to happiness-based) measures. One such measure, the time trade-off (TTO) method, asks subjects to imagine that they have a health condition and will live with it to a specific age, typically 70 . They are then asked how much of their remaining lifespan they would give up to live instead in a healthy state, with a greater willingness to give up life-years indicating a lower evaluation of the health condition (Torrance 1976). The TTO measure is commonly used by medical researchers to determine the disutility created by specific health conditions as part of assessing the cost-effectiveness of interventions designed to prevent or alleviate the conditions (Gold et al. 1996). If people do rapidly adapt emotionally to a given health condition, then one might anticipate that people with the health condition would not be willing to give up much of their remaining lifespan to rid themselves of it.

However, patients' responses to TTO surveys belie this view. For 
example, dialysis patients state that they would give up almost half their remaining years to once again live with normal kidney function (Torrance 1976). Similarly, Smith et al. (2006b) measured the well-being of people with colostomies against those without and failed to find any significant difference in self-reported mood. Yet people with colostomies report, on average, that they would give up almost 15 percent of their remaining lifespan to regain normal bowel function.

It could be objected that the patients who make these decisions have a strong preference for avoiding these health states because they do not appreciate how much they have adapted to their circumstances. Indeed, there is a large literature, including the dialysis study discussed earlier, supporting the idea that people mispredict how happy they would be if they face adversity (Wilson and Gilbert 2003).

Such mispredictions are not limited to healthy persons but can also be seen in patients, who have experienced both health and sickness. In a number of studies, we not only asked healthy people how happy they would be if they were sick but also asked people with illness or disabilities to estimate how happy they would be if they were healthy. Invariably, we found that patients believe they would be substantially happier if they were healthy-indeed, they typically predict an increase in happiness equal to the decrease in happiness predicted by healthy people if they were sick (see Riis et al. 2005; Smith et al. 2006b). Table 1 presents healthy subjects' predictions of how happy they would be if they were on dialysis and dialysis patients' predictions of how happy they would be if they were healthy. Not only did healthy people believe that they would be more miserable if they were on dialysis, but patients on dialysis also estimated that they would be substantially happier if they were not on dialysis. Thus, both groups agreed that they would be substantially happier if healthy than on dialysis, although no such pattern was observed in their self-reported levels of happiness.

In a longitudinal study (Smith et al., forthcoming), we surveyed patients while they were waiting for kidney transplants and asked them about their quality of life and their level of function across various life domains. We also asked them to predict how their quality of life would change in the year following a successful transplant. Then we resurveyed them 1, 6, and 12 months after their transplant. Table 2 summarizes some of our results.

Prior to transplant, patients reported a mean quality of life of 65 (on a $0-100$ scale) and predicted that this would rise to 91 in the year following their transplant. One year after transplant, their quality of life 
S204 / THE JOURnal OF LEGaL StUdies / VOLUME 37 (2) / JUNE 2008

Table 2. Quality-of-Life Reports and Beliefs (0-100)

\begin{tabular}{lccc}
\hline Time of Survey & $\begin{array}{c}\text { Quality-of-Life } \\
\text { Report }\end{array}$ & $\begin{array}{c}\text { 1-Year } \\
\text { Prediction }\end{array}$ & $\begin{array}{c}\text { Recall of } \\
\text { Pretransplant }\end{array}$ \\
\hline $\begin{array}{l}\text { Pretransplant } \\
\text { Posttransplant: }\end{array}$ & 65 & 91 & $\ldots$ \\
1 month & 78 & $\ldots$ & 57 \\
6 months & 80 & $\ldots$. & 55 \\
12 months & 83 &.. & 48 \\
\hline
\end{tabular}

had risen to 83 but significantly less than predicted $(p<.01)$. More important for our current discussion, however, their memory of their pretransplant quality of life had changed. They now believed that their pretransplant quality of life had been lower than it really was. As the table shows, while their own quality of life was increasing through the year, their memory of pretransplant life was changing so that it seemed worse with each passing month. ${ }^{4}$

The similarity of the error made by healthy persons (predicting the happiness of patients) and patients (predicting the happiness of healthy people) probably has a common cause: both groups are likely relying on similar, incorrect, intuitive theories about the impact of disability on happiness. These errors raise the possibility that when patients say they would give up a significant amount of their lifespan or pay a large amount of money to rid themselves of a health condition, they are merely demonstrating their ignorance about hedonic adaptation.

But we think patients deserve more credit than this. While the counterfactuals of patients may result from the same mistakes that healthy persons make, it is difficult to dismiss their responses as purely mistakes.

4. We found similar evidence of recall bias among patients who had received colostomies at the University of Michigan over the last 5 years. In a cross-sectional survey (Smith et al. 2006b), we asked 194 colostomy patients about their current mood and past mood. One hundred of these patients had had their colostomies reversed in the intervening years, an intervention that was not an option for the remaining 94 patients. Yet, despite ridding themselves of a colostomy, these patients were no happier than the group who still had a colostomy, reporting similar levels of quality of life, positive affect, and negative affect. In other words, having a colostomy appeared to have a negligible effect on happiness. Yet when we asked people to reflect on how happy they had been in the past, the groups diverged. Patients with colostomies remembered being significantly happier in the past, while those without colostomies remembered being less happy ( $p<.01$ for interaction). We believe that the most likely explanation for this divergence is that patients' memories were driven by recall bias. Colostomy patients thought back to their happiness before colostomy and believed that they must have been significantly happier then, while those without a colostomy believed the opposite. 
Their belief that they would be happier if they were healthy can be interpreted in a different fashion-as providing a strong indication that they would like to be healthy, whatever the validity of their prediction. ${ }^{5}$

We believe that the main reason that healthy people and sick people want to be healthy is only weakly related to a mistaken belief that disabilities produce unhappiness. Indeed, after conducting numerous studies of the hedonics of health conditions and convincing ourselves that people with serious conditions really are happy, both of us remain steadfast, and we suspect largely unchanged by the research, in our powerful desire to remain healthy.

If the sole goal of pain-and-suffering awards is to compensate people for the emotional consequences of their injuries, then we might favor a system of awards based on the types of measures of experience utilitymoment-to-moment mood-that we have collected in our own research. However, we have fundamental doubts about whether the goal of such awards is simply to compensate for noneconomic damages. We believe that the main reason that most people state a willingness to sacrifice valued resources for health is not that they underestimate adaptation but that happiness is not the only thing that matters in life. Hence, there are noneconomic damages that warrant compensation even when people fully adapt, emotionally, to a sickness or injury.

\section{WHAT HEDONIC MEASURES MISS}

Imagine, for a moment, that you have experienced kidney failure, are receiving dialysis three times a week, and have substantially-even completely_adapted emotionally to the situation. In other words, you are as happy now as you were before experiencing kidney failure. Let us also assume, for the purposes of our argument, that you are able to maintain your normal full-time job or have found alternative employment that is not only gratifying but that gives you the same financial rewards as your previous employment. Is there any way in which you are suffering now that deserves compensation, despite the economic and emotional neutrality of your current circumstances? We contend that there are many things that matter to people in their lives independent of how those circumstances influence their long-term emotions.

5. Indeed, the first author has spoken to kidney transplantation patients who say that only after being relieved of kidney failure did they realize how unhappy they used to be when they had to receive dialysis three times a week. 
S206 / THE JOURNAL OF LEGAL STUdiES / VOLUME 37 (2) / JUNE 2008

\subsection{Capabilities}

Disability, by definition, involves the loss of some ability, some kind of normal physical functioning. It could be, and in fact has been, argued that such abilities, or capabilities, are important for welfare even if they have little or no impact on hedonics. This is the central insight of the capabilities approach to welfare proposed by Amartya Sen $(1985,1992)$ and elaborated on by Martha Nussbaum (2000). It was originally designed to deal with problems of social injustice, and specifically the idea that people may be content with poor social and physical conditions or injustice because they have adapted to them or have never experienced anything else. As Nussbaum (2000, p. 114) expresses it, aspirations for a better life can be squelched by "habit, fear, low expectations, and unjust background conditions that deform people's choices and even their wishes for their own lives." Sen and Nussbaum delineate a series of central human capabilities, such as health, freedom from assault, political voice, property rights, equal employment, and access to education, as well as others that involve self-actualization, such as expression of emotion, affiliation with others, and recreation, that they view as universal desiderata. Some of these capabilities, such as health and recreation, are very likely to be undermined by disability and hence, it could be argued, warrant compensation even if an individual is unaffected hedonically because of adaptation or for other reasons.

\subsection{Emotional and Experiential Variety}

Consider a person who suffers brain damage from an industrial accident and is turned into a happy simpleton because of the injury. It is possible for this person to be emotionally happier than he was prior to the injury, his neuroses dampened by brain damage, his balance of positive and negative affect now much better than before. Would this victim have no grounds for a pain-and-suffering award? John Stuart Mill ([1863] 1973) addressed this question when he stated that it would be better to be a human dissatisfied than a pig satisfied. Clearly, many philosophers (Griffin 1989), as well as both authors of this paper, believe that there are dimensions of richness of experience and complexity and sophistication of thought that have value over and above simple happiness. To the extent that disability limits such experience, according to this perspective, it detracts from welfare, even if it does not detract from happiness. 


\subsection{Altruistic and Moral Motives}

Yet a third category of desired things that may be imperfectly, or even negatively, related to happiness are those that one does out of duty or a sense of morality. People take care of children and aging parents, even when those duties seem onerous and detract from happiness. Thus, for example, becoming a burden on one's children or parents, instead of a caretaker of them, should therefore be counted as a loss, even if it is not accompanied by acute mental suffering.

\subsection{The Myth of "Making Whole"}

A final nail in what we would like to think is the coffin of a hedonic interpretation of pain-and-suffering awards is the observation that such awards cannot possibly compensate for the conditions for which they are intended to compensate. This stands in sharp contrast to common ways of viewing pain-and-suffering awards.

The idea of giving a victim-someone who has become blinded or paraplegic or severely brain damaged-an amount of money that would make them whole almost certainly is not possible. For a start, in many cases, as we have discussed at length, people emotionally adapt to injuries, so there is nothing that needs to be made whole, in an emotional sense. In these cases, the goal of a pain-and-suffering award cannot be to restore people to their previous emotional state, since they have largely returned to that emotional state without such compensation. In cases in which people do not recover emotionally from serious injuries, on the other hand, there is no evidence that we are aware of that giving them monetary compensation will restore them to their previous emotional state, so it is often impossible, in any case, to make people "whole." Physical injuries and monetary awards seem like examples of things that legal scholars have referred to as being incommensurable (Sunstein 1994).

\section{HOW tO VALUE PAIN AND SUFFERING: A TRIPARTITE PROPOSAL}

What does it mean to compensate someone for pain and suffering resulting from an injury to which they have emotionally adapted? We contend that the compensation should include hedonic losses associated with the injury-any loss of pleasure or increase in pain and miserybut should also incorporate other factors. Thus, a person who suffers a brain injury, and has become a happy simpleton, has experienced an 
important loss that deserves compensation, even thought his momentto-moment mood may be better than ever.

Pain-and-suffering awards, we believe, should be based on a mixture of factors. In part, they should capture the value that society puts on the noneconomic elements of an injury, to deter people from injuring others. If no value is placed on pain and suffering, then potential causers of damage will not sufficiently internalize the risks they impose on society (Arlen 1990, 1993). Damages for pain and suffering are also, in part, intended to provide some relief from actual hedonic pain and suffering, even if they do not restore individuals to their former level of happiness. How, then, is it possible to place a value on pain and suffering once one recognizes that compensating pain and suffering in a literal hedonic sense is impossible and in any case normatively indefensible? We believe that the key is to abandon the illusion that damage awards should compensate for hedonic losses. Instead, we believe, damages should be calibrated to an evaluation of the overall losses imposed by the injury, including but not limited to hedonic effects. We propose a specific proposal for how to assess such damages, breaking the problem into three decisions, each to be made by the people who are the most competent to make it.

The first part of the decision would involve convening a representative panel of citizens to categorize and rank a list of injuries from worst to least bad. The second would involve legislation to determine a maximum value for noneconomic damages and an appropriate value for each rank or category of injury. The third, which would be the task of juries, would be to position the particular damages of a specific plaintiff within the list of injuries ranked by the panel of citizens. We have no idea if such a solution would be politically feasible or legally permissible, but we suspect that it could attain more normatively justifiable awards and diminish problems of vertical and horizontal inequity.

\subsection{Ranking and Categorizing Representative Injuries}

The first part of our proposed solution involves recruiting a random panel of citizens to develop a thorough, albeit incomplete, list of injuries categorized into groups, with the groups ranked on the basis of the appropriate level of compensation for those particular injuries. Loss of a pinkie toe, for example, might be in one of the most mild categories of injury, because such an injury has almost no long-term emotional consequences and has negligible effects on physical, social, and job functioning. A below-the-knee leg amputation without significant chronic pain would be ranked as a more severe injury, and an amputation ac- 
companied by serious pain would be ranked as being even more severe. Decisions about an injury's proper category would take into account not only the emotional consequences of the injury but also the person's ability to function across important life domains-social functioning, work functioning, sexual functioning, sleep, and the like.

Panelists would hear testimony from experts who would inform them about the likely material consequences of an injury (for example, whether it would be possible for an individual with the injury to drive a car and what type of job, if any, he or she might be capable of holding). In addition, experts would be permitted to testify about evidence concerning the degree to which people do or do not adapt hedonically to the particular condition. ${ }^{6}$ We are unsure of if such testimony would have much impact on rankings, but this is the main point at which it would enter into the valuation of damages.

Such an approach to ranking would have a number of benefits. First, the panelists would be ranking injuries in a comparative fashion. Considerable research, including research specifically related to legal damages, suggests that comparative judgments are superior to one-at-a-time judgments (Hsee, Blount, and Bazerman 1999; Sunstein et al. 2002; Ariely et al. 2003). Second, the panel would have both the time and the expert input needed to make informed judgments. Yet, unlike experts, as a representative sample of the population, such a panel would be largely immune to the specific interests that can cloud experts' judgment and make it impossible for such experts to reach a consensus.

Of course, there are many details that would need to be worked out about how best to create such a grouping of citizens, who should be involved in making the list, and so on. But such a task is possible. For example, in the early 1990s the state of Oregon created a list of health conditions to help it allocate its Medicaid funds more efficiently. The goal was to determine which health conditions benefit most from treatment and are most important to treat and which, therefore, would receive

6. Such inputs could be implemented, of course, only if there are substantial data documenting the impact of common injuries on broad measures of well-being. But these data are rapidly accumulating and could readily be made available for the injuries being ranked. This approach could help to eliminate the influence of mispredictions and misrememberings on awards. It would likely lead to smaller awards for many physical disabilities to which most people emotionally adapt, while potentially leading to larger awards for conditions causing physical pain, which typically have a larger effect on subjective wellbeing than mere loss of physical function. The general public typically overestimates how much physical disabilities affect well-being but underestimates how much pain influences subjective well-being (Damschroder et al. 2005). 
funding priority, eliminating funding for less important and less valuable treatments and thereby saving enough money to expand Medicaid coverage to a wider group of people (Ubel 2000). In developing this list, Oregon convened a series of community meetings to see what people valued most in health-care interventions. The Oregon Health Commission organized a number of committees to develop different parts of the list. They put out a preliminary list and received feedback and made many changes to the list over several iterations before arriving upon one that was acceptable to a majority of people. That list has been in existence now for well more than a decade and has continued to play an important role in Oregon's Medicaid system. In addition, our proposal has other legal precedents, such as workers' compensation claims, which are frequently based on preexisting lists of work-related injuries. For example, the Iowa Worker's Compensation Manual (Iowa Workforce Development 2007) stipulates benefits for loss of a thumb that are twice as great as for loss of a second finger, and 12/7th as great as for loss of a first finger, but just shy of a quarter as great for loss of an arm. ${ }^{7}$

\subsection{Determining Money Amounts}

Given the logical and practical impossibility of determining an amount of money that would make a plaintiff "whole," we believe that the task of determining the general value of monetary awards is, or should be, a political one and not subject to the idiosyncrasies of individual juries and judges. The real issue, as highlighted by Jennifer Arlen (1985) in a paper on damages for accidental death, is to determine levels of compensation that make the correct trade-off between compensating those who are harmed and limiting the liability of those who harm others. That is, individuals not only are directly affected by receiving damages for pain and suffering; they also have to pay such damages, either directly or indirectly, when the firms they are employed by, own, and buy goods from pay such damages or when the government they finance through taxes pays damages.

One possible mechanism for determining damages in a specific case would be for federal or state legislators to determine a maximum value for an award of pain and suffering. Determination of such a maximum could, and probably should, be informed by the list produced in the process outlined in Section 5.1. That is, legislators would be in a better

7. The values represent the number of weeks of benefits payable for 100 percent loss, or loss of use, of the body member. 
position to specify a maximum if they had full knowledge of not only to what type of injury this maximum would apply but also the range and variety of lesser possible injuries.

Although this might seem like a difficult task for a legislature to tackle, in fact, several state legislatures have already dealt with a very closely related problem-the problem of assigning a damage cap for certain types of damages. There is some evidence that existing damage caps sometimes distort awards, in some cases constraining awards that, according to empirical analyses, should have been larger (Viscusi and Born 2005) and in other cases actually increasing small awards by creating a kind of anchor or focal point for awards (Pogarsky and Babcock 2001). The ranking procedure we have outlined would help to avoid both of these problems.

Once a monetary cap has been established, the award could be determined by using the cardinal score, as described above. As an alternative, for example, panelists participating in stage 1 could be given information on the maximum award and then set a range of awards for each category of injury. If they settled, say, on 10 categories of injury, the top category may qualify for between 80 and 100 percent of the maximum award. The next category may qualify for between 70 and 90 percent of the maximum. This would allow for overlap between categories and for a range of awards based on the particulars of the individual victim. Exactly how monetary awards would be assigned to categories would need to be resolved. The main point of the proposed method, however, is to separate the two tasks-ranking injuries on the basis of hedonic and nonhedonic factors and determining appropriate monetary awards-and to separate both of these from the task given to juries.

\subsection{The Task of Juries}

As we have already pointed out, jurists are likely to mispredict the hedonic consequences of many injuries, overestimating the long-term impact of physical disabilities while underestimating the impact of factors such as chronic pain. For this reason, juries should not be asked to make such determinations. In addition, there are several other tasks at which juries have been shown to fail. As documented in the empirical literature on damages, the existing jury system produces a great degree of horizontal inequity; similar plaintiffs often end up with vastly different awards. Such inequities occur, in part, because the current system requires juries to make decisions that they are ill-equipped to make-most 
notably to convert pain and suffering into inherently incommensurable monetary terms (Sunstein 1994). Juries are prone to affective forecasting errors, anchoring effects, and random sources of variability from jury to jury, which leaves the level of any given award unacceptably arbitrary.

But beyond the legal mandate for use of juries and the psychological and cultural investment in the jury process, the jury system has an important strength that the proposed framework seeks to exploit. Each injury is, in fact, unique and fits in with the victim's preinjury life in a unique fashion; the jury system creates the opportunity to individualize awards to take account of each victim's unique circumstances.

While people perform poorly in making certain types of judgments and decisions, such as translating between incommensurable scales, they are extremely good at other types of tasks. Specifically, people are very good at ranking things, comparing things, and categorizing them. The task that we propose to give to juries draws on exactly these capabilities. We propose to give juries the task of determining which group of injuries ranked by the panel of citizens proposed in Section 5.1 most closely resembles that of the victim at hand. In addition, juries could help determine if the victim has extenuating circumstances that should drive the award to either the lower or upper end of acceptable compensation for that group of injuries. For example, a victim may have a spinal cord injury at the level of C-7. A jury's job will be to determine if the evidence of this injury is compelling and if there is culpability and then to judge into which group of injuries this injury best fits. If this injury is common enough, it might actually already be on the list, which would simplify the judgment. If it is not on the list, then the jury will need to determine how the injury at hand compares in severity to the ordered grouping of injury categories. Finally, the jury would be asked to determine if this particular victim is suffering more or less than the average person with such an injury.

Our proposal does not do away with jury trials but instead enables juries to involve themselves in the kind of judgments they are best suited to make. We cannot predict how our proposal would influence the relative size of awards for various injuries, although we anticipate that some purely physical injuries-the kind that do not cause much pain or loss of function-will receive relatively smaller awards. The loss of a finger, for example, may end up lower on the severity list than less visible injuries that have more emotional or functional impact. It seems unlikely, however, that the majority of awards would be unchanged under the new system. It would be quite a coincidence if a careful assessment of 
the functional impact of common injuries did not cause significant departures from the amounts awarded by the current system, which gives such large play to affective forecasting errors. And even if this unlikely scenario came to pass, at least we would have more confidence in our system than we currently do.

\section{CONCLUSION}

In this paper we have argued that pain-and-suffering awards cannot, and should not, be measures of either subjective pain and suffering or what it would take to alleviate pain and suffering. Instead, awards should be based on a determination of the impact of the injury on both hedonic and nonhedonic aspects of experience-on how an injury influences not only people's long-term moods and feelings but also their ability to function in important life domains.

We have also argued that individual juries are not equipped to determine the emotional impact of specific injuries and, therefore, that a separate deliberative body should review a list of the most common injuries and rank them on the basis of their impact. By removing juries from having to perform this difficult task, we can focus them, instead, on doing the tasks they are best equipped to accomplish. By relieving juries of this task, we not only avoid problems created by hedonic adaptation but also alleviate other problems that have plagued the jury system.

The current system for determining the value of pain-and-suffering awards evolved during a time when experts were largely ignorant about hedonic adaptation or insights from decision research that can help identify what kind of decisions juries are equipped, and not equipped, to make. The determination of pain-and-suffering awards should be revised to take account of recent advances in understanding human judgment and decision making.

\section{REFERENCES}

Abel, Richard. 2006. General Damages Are Incoherent, Incalculable, Incommensurable, and Inegalitarian (but Otherwise a Great Idea). DePaul Law Review 55:253-329.

Ariely, Dan, George Loewenstein, and Drazen Prelec. 2003. Coherent Arbitrar- 
iness: Stable Demand Curves without Stable Preferences. Quarterly Journal of Economics 118:73-106.

Arlen, Jennifer H. 1985. An Economic Analysis of Tort Damages for Wrongful Death. New York University Law Review 60:1113-36.

- 1990. Reconsidering Efficient Tort Rules for Personal Injury: The Case of Single Activity Accidents. William and Mary Law Review 32:41-103.

— 1993. Compensation Systems and Efficient Deterrence. Maryland Law Review 52:1093-1136.

Bagenstos, Samuel R., and Margo Schlanger. 2006. Hedonic Damages, Hedonic Adaptation, and Disability. Public Law and Legal Theory Research Paper No. 06-09-01. Washington University School of Law, St. Louis.

Baron, Jonathan, David A. Asch, Angela Fagerlin, Christopher Jepson, George Loewenstein, Jason Riis, Margaret G. Stineman, and Peter A. Ubel. 2003. Effect of Assessment Method on the Discrepancy between Judgments of Health Disorders People Have and Do Not Have: A Web Study. Medical Decision Making 23:422-34.

Damschroder, Laura J., Brian J. Zikmund-Fisher, and Peter A. Ubel. 2005. The Impact of Considering Adaptation in Health State Valuation. Social Science and Medicine 61:267-77.

Frederick, Shane, and George Loewenstein. 1999. Hedonic Adaptation. Chapter 16 in Foundations of Hedonic Psychology: Scientific Perspectives on Enjoyment and Suffering, edited by Daniel Kahneman, Ed Diener, and Norbert Schwarz. New York: Russell Sage Foundation.

Geistfeld, Mark. 1995. Placing a Price on Pain and Suffering: A Method for Helping Juries Determine Tort Damages for Nonmonetary Injuries. California Law Review 83:773-852.

Gold, Marthe R., Joanna E. Siegel, Louise B. Russell, and Milton C. Weinstein, eds. 1996. Cost-Effectiveness in Health and Medicine. New York: Oxford University Press.

Griffin, James. 1989. Well Being: Its Meaning, Measurement, and Moral Importance. Oxford: Clarendon Press.

Hsee, Christopher K., Sally Blount, and Max Bazerman. 1999. Preference Reversals between Joint and Separate Evaluations of Options: A Review and Theoretical Analysis. Psychological Bulletin 125:576-90.

Iowa Workforce Develpment. 2007. Division of Workers' Compensation. Iowa Workers' Compensation Manual. Des Moines: Division of Workers' Compensation. http://www.iowaworkforce.org/wc/2007ratebook.pdf.

Lacey, Heather P., Angela Fagerlin, George Loewenstein, Dylan M. Smith, Jason Riis, and Peter A. Ubel. Forthcoming. Unbelievably Happy? Exploring Whether Scale Recalibration Accounts for the Happiness Gap. Health Psychology.

Lucas, Richard E. 2005. Time Does Not Heal All Wounds: A Longitudinal Study of Reaction and Adaptation to Divorce. Psychological Science 16:946-50. 
Lucas, Richard E., Andrew E. Clark, Yannis Georgellis, and Ed Diener. 2004. Unemployment Alters the Set Point for Life Satisfaction. Psychological Science 15:8-13.

Mill, John Stuart. [1863] 1973. Utilitarianism. Pp. 399-472 in The Utilitarians. Garden City, N.Y.: Anchor Press/Doubleday.

Nusbaum, Martha. 2000. Sex and Social Justice. New York: Oxford University Press.

Oswald, Andrew J. and David G. Blanchflower. 2004. Money, Sex, and Happiness: An Empirical Study. Scandinavian Journal of Economics 106: 393-416.

Pogarsky, Greg, and Linda Babcock. 2001. Damage Caps, Motivated Anchoring, and Bargaining Impasse. Journal of Legal Studies 30:143-59.

Price, Douglas L. 1993. Hedonic Damages: To Value a Life or Not to Value a Life? West Virginia Law Review 95:1055-90.

Riis, Jason, George Loewenstein, Jonathan Baron, Christopher Jepson, Angela Fagerlin, and Peter A. Ubel. 2005. Ignorance of Hedonic Adaptation to Hemodialysis: A Study Using Ecological Momentary Assessment. Journal of Experimental Psychology: General 134:3-9.

Schwartz, Victor E., and Cary Silverman. 2004. Hedonic Damages: The Rapidly Bubbling Cauldron. Brooklyn Law Review 69:1037-71.

Schwarz, Norbert, and Fritz Strack. 1999. Reports of Subjective Well-Being: Judgmental Processes and Their Methodological Implications. Pp. 61-84 in Well-Being: The Foundations of Hedonic Psychology, edited by Daniel Kahneman, Ed Diener and Norbert Schwarz. New York: Russell Sage Foundation.

Sen, Amartya. 1985. Commodities and Capabilities. Amsterdam: NorthHolland.

. 1992. Rationality and Freedom. Cambridge, Mass.: Harvard University Press.

Smith, Dylan M., Kenneth M. Langa, Mohammed U. Kabeto, and Peter A. Ubel. 2005. Health, Wealth, and Happiness: Financial Resources Buffer Subjective Well-Being after the Onset of a Disability. Psychological Science 16:663-66. Smith, Dylan M., George Loewenstein, Aleksandra Jankovich, Christopher Jepson, H. Feldman, and Peter A. Ubel. Forthcoming. Mispredicting and Misremembering: Patients Overestimate Improvements in Quality of Life after Renal Transplant. Health Psychology.

Smith, Dylan M., George Loewenstein, Aleksandra Jankovich, and Peter A. Ubel. 2008. The Dark Side of Hope: Lack of Adaptation to Temporary versus Permanent Colostomy. Working paper. University of Michigan, Ann Arbor.

Smith, Dylan M., Norbert Schwarz, Todd Roberts, and Peter Ubel. 2006a. Why Are You Calling Me? How Study Introductions Change Response Patterns. Quality of Life Research 15:621-30.

Smith, Dylan M., Ryan L. Sherriff, Laura Damschroder, George Loewenstein, and Peter A. Ubel. 2006b. Misremembering Colostomies? Former Patients 
S216 / the JOURnal OF LEGal StUdies / VOLUME 37 (2) / JUNE 2008

Give Lower Utility Ratings than Do Current Patients. Health Psychology 25: 688-95.

Sunstein, Cass R. 1994. Incommensurability and Valuation in Law. Michigan Law Review 92:779-861.

Sunstein, Cass R., Daniel Kahneman, David Schkade, and Ilana Ritov. 2002. Predictably Incoherent Judgments. Stanford Law Review 54:1153-1216.

Torrance, George W. 1976. Social Preferences for Health States: An Empirical Evaluation of Three Measurement Techniques. Socioeconomic Planning Science 10:129-36.

Tyc, Vida L. 1992. Psychosocial Adaptation of Children and Adolescents with Limb Deficiencies: A Review. Clinical Psychology Review 12:275-91.

Ubel, Peter A. 2000. Pricing Life: Why It's Time for Health Care Rationing. Cambridge, Mass.: MIT Press.

- 2006. You're Stronger than You Think: Tapping the Secrets of Emotionally Resilient People. New York: McGraw-Hill.

Ubel, Peter A., Aleksandra Jankovic, Dylan Smith, Kenneth M. Langa, and Angela Fagerlin. 2005. What Is Perfect Health to an 85-Year-Old? Evidence for Scale Recalibration in Subjective Health Ratings. Medical Care 43:1054-57.

Viscusi, W. Kip. 1988. Pain and Suffering in Product Liability Cases: Systematic Compensation or Capricious Awards? International Review of Law and Economics 8:203-20.

Viscusi, W. Kip, and Patricia H. Born. 2005. Damages Caps, Insurability, and the Performance of Medical Malpractice Insurance. Journal of Risk and Insurance 72:23-43.

Wilson, Timothy D., and Daniel T. Gilbert. 2003. Affective Forecasting. Pp. 345-411 in vol. 35 of Advances in Experimental Social Psychology, edited by Mark P. Zanna. San Diego, Calif.: Academic Press.

Wortman, Camille B., and Roxane C. Silver. 1987. Coping with Irrevocable Loss. Pp. 189-235 in Cataclysms, Crises, and Catastrophies: Psychology in Action. Master Lecture Series 6. Washington, D.C.: American Psychological Association. 